\title{
Kesesuaian Lahan untuk Tanaman Kayu Putih sebagai Strategi Modifikasi Konservasi dan Kepentingan Nilai Tambah Ekonomi di Desa Cikembang, Kecamatan Kertasari, Kabupaten Bandung
}

\section{Land Suitability for Eucalyptus Plants as a Conservation Modification Strategy and Economic Value Added Interests in Cikembang Village, Kertasari District, Bandung Regency}

\author{
ANDIS PRISWANTORO ${ }^{1,2 *}$, NANA SULAKSANA ${ }^{1,3}$, CIPTA ENDYANA ${ }^{1,3,4}$, ANGGORO TRI MURSITO $^{5}$ \\ ${ }^{1}$ Sekolah Pascasarjana, Program Studi Inovasi Regional, ${ }^{3}$ Fakultas Teknik Geologi, ${ }^{4}$ Pusat Riset Citarum, Universitas Padjadjaran \\ ${ }^{2}$ Biro Perencanaan dan Keuangan, ${ }^{5}$ Pusat Penelitian Geoteknologi, Lembaga Ilmu Pengetahuan Indonesia \\ Email: andis18002@mail.unpad.ac.id; andis.priswantoro@gmail.com
}

\begin{abstract}
Cikembang Village, Kertasari District, Bandung Regency, is located in the Upper Citarum Sub-watershed. Cikembang, one of the water catchment villages, is a conservation area with eucalyptus plants. Eucalyptus plants in the category of Fast-Growing Species (FGS) can accelerate the process of succession of critical lands, restoration of peat ecosystems, are very adaptive to cultivate with agroforestry systems, support food security. However, the implementation of eucalyptus plants in Cikembang Village needs to be analyzed its impact on the conservation function and the importance of economic value-added. This study aims to form a conservation modification strategy and the importance of added value to the economy of eucalyptus cultivation by taking into account land suitability and its limiting factors. The soil fertility level approach is promising for eucalyptus growth in three land locations, namely: wet soil/Th, slope/Tk, soil near springs/Tm, with attributes of elevation, slope, rainfall, temperature, acidity, and soil organic matter. With the storie method's assessment, the soil is in the N1 category (currently unsuitable), and the root square is produced while the soil is in the S3 category (slightly marginal). The strategy for obtaining land use to accommodate cropping patterns for conservation and agricultural interests is by applying the silvicultural system techniques (integrating plant species, environmental modification, making terraces, setting spacing, and managing fertilization maintenance, including pest control). The study also tried to accommodate the approach to producing eucalyptus leaves as raw material for eucalyptus oil processing becomes an economic added value by refining eucalyptus oil.
\end{abstract}

Keywords: eucalyptus, strategy, modification, conservation, added value

\begin{abstract}
ABSTRAK
Kawasan Desa Cikembang, Kecamatan Kertasari, Kabupaten Bandung, terletak di Sub DAS Citarum Hulu. Cikembang salah satu desa tangkapan air menjadi daerah konservasi dengan tanaman kayu putih. Tanaman kayu putih kategori fast growing species (FGS) dapat mempercepat proses suksesi lahan kritis, restorasi ekosistem gambut, sangat adaptif dibudidayakan dengan sistem agroforestri, mendukung ketahanan pangan. Namun demikian, implementasi tanaman kayu putih di Desa Cikembang perlu dianalisis dampaknya terhadap fungsi konservasi dan kepentingan nilai tambah ekonomi. Penelitian ini bertujuan untuk membentuk strategi modifikasi konservasi dan kepentingan nilai tambah ekonomi budidaya tanaman kayu putih dengan memperhatikan kesesuaian lahan dan faktor pembatasnya. Pendekatan tingkat kesuburan tanah cukup menjanjikan untuk pertumbuhan kayu putih di tiga lokasi lahan yaitu: tanah basah/Tb, tanah kemiringan/Tk, tanah dekat mata air/Tm, dengan atribut elevasi, lereng, curah hujan, suhu, dan keasaman serta organik tanah. Dengan menggunakan pendekatan metode storie, diketahui bahwa tanah Desa Cikembang termasuk ke dalam kategori N1 (saat ini tidak sesuai), dan dengan menggunakan metode root square, dihasilkan bahwa tanah termasuk kategori S3 (sedikit marginal). Strategi yang digunakan untuk memperoleh tata guna lahan yang mengakomodasi pola tanam untuk konservasi dan kepentingan pertanian adalah pendekatan aplikasi teknik sistem silvikultur (pemaduan elemen spesies tanaman, modifikasi lingkungan, pembuatan teras, pengaturan jarak tanam, pengaturan pemupukan, pemeliharaan, termasuk pengendalian hama) serta pendekatan produksi daun tanaman kayu putih sebagai bahan baku olahan minyak kayu putih menjadi nilai tambah ekonomi dengan penyulingan minyak kayu putih.
\end{abstract}

Kata kunci: kayu putih, strategi, modifikasi, konservasi, nilai tambah 


\section{PENDAHULUAN}

\subsection{Latar Belakang}

Tanah Sunda atau yang dikenal sebagai Bumi Parahyangan memiliki potensi kekayaan alam yang luar biasa. Di lain pihak selain potensi kekayaan alam, Bumi Parahyangan juga memiliki potensi bencana. Deretan gunung berapi, baik yang masih aktif maupun istirahat menjadi barikade atau pembatas utama dataran tinggi Bandung yang berada dalam wilayah Cekungan Bandung(1). Posisi tersebut membuat Bandung Selatan termasuk wilayah cekungan Bandung dengan potensi sumber daya alam yang melimpah, diantaranya sumber daya air, panas bumi, dan pertambangan. Sumber air berderet di sepanjang lereng gunung-gunung Bandung Selatan tersebut, salah satunya menjadi hulu sumber daya air yaitu situ Cisanti yang berada di kaki Gunung Wayang yang merupakan hulu dari Sungai Citarum yang menjadi sungai terpanjang di Jawa Barat ${ }^{(1)}$. Saat ini, kondisi DAS Citarum mengalami kerusakan yang disebabkan antara lain penebangan hutan di wilayah hulu (konservasi), penggundulan lahan tanpa perencanaan dan pengawasan, erosi tanah di hulu yang menyebabkan tingginya sedimentasi di daerah tengah dan hilir sehingga menyebabkan air sungai meluap melebihi kapasitas dan mengakibatkan banjir ${ }^{(2)}$. Salah satu arah kebijakan, strategi menurunkan sedimentasi di DAS Citarum dengan pengurangan erosi melalui penanganan lahan kritis $^{(2)}$.

Pengelolaan kawasan lindung di Desa Cikembang dengan reboisasi/penghutanan kembali dengan jenis tanaman kayu putih (Melaleuca Cajuputi sub sp. cajuputi), merupakan wilayah kegiatan Sektor 23 Satgas Citarum Harum. Kegiatan persemaian, penanaman dan pemeliharaan kayu putih dilaksanakan bersama dengan kelompok tani penggarap dengan beberapa titik lokasi Satgas 23, Citarum Harum. Tanaman kayu putih merupakan salah satu tanaman sumber daya alam yang tidak terbatas hanya menghasilkan kayu, akan tetapi dapat menjadikan banyak manfaat lainnya termasuk kategori FastGrowing Species (FGS) untuk dapat digunakan proses percepatan konservasi lahan kritis seperti kawasan $\operatorname{karst}^{(3)}$ serta restorasi ekosistem gambut( ${ }^{(3)}$. Hal ini sesuai perubahan paradigma dari pengelolaan sumberdaya hutan berorientasi kayu (Timber Oriented Management) kepada pengelolaan berbasis sumberdaya (Resources Based Management), salah satunya bentuk pemanfaatan hasil hutan non kayu berupa kayu putih ${ }^{(4)}$. Tanaman ini dapat memberikan manfaat secara ekologi, ekonomi, serta sosial( ${ }^{(3)}$. Kayu putih sebagai tumbuhan penghasil minyak atsiri/minyak kayu putih yang dihasilkan dari daunnya, dengan mengandung sekitar $0,97 \%$ minyak atsiri(4). Minyak kayu putih ini dapat dihasilkan secara berkelanjutan tanpa merusak hutan, sehingga minyak kayu putih merupakan hasil hutan non kayu (non timber forest product).

Evaluasi keberhasilan tanaman dan analisa faktor lingkungan fisik penting dilakukan untuk mengetahui karakteristik lahan agar tercapainya pengelolaan tanaman kayu putih yang lebih baik $^{(5)}$. Karakteristik lahan tersebut digunakan sebagai strategi modifikasi konservasi dengan penambahan lokasi reboisasi di kawasan pengelolaan serta teknik pengolahan, pengolahan lahan konservasi. Selanjutnya melihat kebutuhan minyak kayu putih di dalam negeri sampai saat ini diperkirakan masih mengalami kekurangan dan masih diperlukan produk komplementer berupa minyak eucalyptus impor $^{(6)}$. Sehingga jumlah produksi untuk pemenuhan kebutuhan, terbuka peluang memproduksi minyak kayu putih di Indonesia dengan meningkatkan keterlibatan masyarakat petani/kelompok tani yang lebih intensif( ${ }^{(7)}$. Evaluasi lahan untuk strategi modifikasi konservasi dengan penambahan penanaman pohon kayu putih akan dapat lestari dengan keterlibatan kerjasama dengan masyarakat, petani/kelompok, serta penyulingan minyak kayu putih dapat menjadi nilai tambah ekonomi/perekonomian masyarakat serta dapat mendorong motivasi menanam pohon kayu putih $^{(8)}$. Adanya potensi mesin terpasang penyulingan minyak atsiri/minyak kayu putih di Kecamatan Kertasari, Kabupaten Bandung, dapat mendukung produksi/penyulingan minyak kayu putih (Gambar 1). Sampai saat ini, minyak kayu putih menjadi produksi Hasil Hutan Non Kayu (HHNK) bernilai ekonomi tinggi dengan potensi pasar yang cukup propektif(3).

Penelitian ini memilih evaluasi kesuaian lahan melalui pola matching systems dengan membandingkan suatu karakteristik lahan dengan prasyarat tumbuh tanaman kayu putih serta perhitungan nilai indeks lahan metode storie dan root square melalui persamaan matematis ${ }^{(3,9)}$. Kesesuaian lahan bagi pengembangan tanaman kayu putih untuk kepentingan komersial perlu dilakukan sehingga produktivitas kayu putih dapat ditingkatkan dengan pendekatan teknik silvikultur yang tepat ${ }^{(3)}$. Pemilihan metode storie ini diperkuat dengan prosedur evaluasi kesesuian lahan berbasis metode root square yang menghasilkan luaran informasi lebih realistis sebagai acuan untuk budidaya sektor kehutanan, perkebunan, serta pertanian ${ }^{(3)}$.

Berdasarkan latar belakang di atas lokasi penelitian lahan di Desa Cikembang meskipun 
memliki daya adaptasi yang tinggi terhadap kondisi lingkungan ${ }^{(3)}$, akan tetapi untuk pengembangan tanaman di lahan konservasi di Desa Cikembang sebagai daerah tangkapan air Sub DAS Citarum Hulu seluas sekitar $\pm 400 \mathrm{Ha}$, perlu dilakukan penelitian kesesuaian lahan sebagai strategi modifikasi pengelolaan untuk tanaman kayu putih sebagai fungsi konservasi dan nilai tambah ekonomi. Sehingga pola tanam dapat mengakomodasi kepentingan konservasi dan kepentingan pertanian. Mengingat lahan sebagai lingkungan fisik yang terdiri atas iklim, relief, tanah, air, dan vegetasi serta benda yang diatasnya sepanjang berpengaruh terhadap penggunaan lahan, termasuk didalamnya paling besar yang disebabkan oleh kegiatan manusia di masa lalu dan sekarang untuk kepentingan pengguna lahan ${ }^{(10)}$. Karakteristik lahan yang menjadi habitat kayu putih ini dapat mendukung produktivitas kayu putih ${ }^{(3)}$.

\subsection{Tujuan Penelitian}

Kesesuaian lahan digunakan untuk tujuan strategi pengelolaan budidaya tanaman kayu putih dengan memperhatikan faktor pembatasnya. Hasil penelitian berupa arahan/rekomendasi modifikasi(11) pengelolaan sebagai pengakomodasi kepentingan konservasi dan kepentingan pertanian pengembangan tanaman kayu putih untuk nilai tambah ekonomi di lahan konservasi di Sub DAS Citarum Hulu di Desa Cikembang, Kecamatan Kertasari, Kabupaten Bandung.

\section{BAHAN DAN METODE}

\subsection{Bahan}

Bahan yang digunakan dalam penelitian ini adalah dengan menggunakan sampel tanah yang diambil dari lokasi penelitian. Pengambilan sampel dilakukan dengan menggunakan cangkul dan plastik sebagai wadah tanah. Kemudian sampel tersebut dibawa ke
Laboratorium Tanah Universitas Padjadjaran (UNPAD) untuk mendapatkan analisa kimia kandungan tanah.

\subsection{Metode}

Waktu penelitian dilakukan pada bulan April sampai dengan bulan Mei Tahun 2020. Lokasi penelitian di Sub DAS Desa Cikembang, merupakan Sub DAS dari DAS Citarum Hulu, secara geografis terletak pada $107^{\circ} 37^{\prime} 12^{\prime \prime}$ BT $107^{\circ} 44^{\prime} 24^{\prime \prime}$ BT and 07ㅇ'31,2"LS - 07'39'12 LS. Desa Cikembang berada di wilayah Kecamatan Kertasari, Kabupaten Bandung.

Data Analisa kesuburan tanah 3 (tiga) lokasi penelitian dibuat dalam tabel dengan kode tanah diberikan sesuai dengan kondisi pengamatan fisik tanah, yaitu: (1) tanah basah/Tb, (2) tanah kemiringan/Tk, (3) tanah dekat mata air/Tm. Selanjutnya evaluasi kesesuaian lahan dilakukan dengan pola matching systems yaitu membandingkan hasil analisis kimia tanah dengan prasyarat tumbuh tanaman kayu putih(3).

Evaluasi kesesuaian lahan didasarkan pada Framework of Land Evaluation (FAO 1976) dengan menggunakan kategori struktur klasifikasi yaitu 4 kategori, antara lain: ordo, kelas, sub kelas, dan unit. Kategori kesesuian lahan diuraikan dalam Tabel 1, dengan menggunakan metode storie dan root square ${ }^{(3,9)}$

(a) Metode Storie:

$$
I=A \times(B \div 100) \times(C \div 100)
$$

(b) Metode Root Square:

$$
I=R \min \sqrt{ }(A \div 100) \times(B \div 100)
$$

di mana I adalah indeks dari lahan A, B, C, yang mewakili skor lahan yang sesuai terhadap syarat tumbuh tanaman kayu putih. Kesesuaian atribut lahan terhadap prasyarat tumbuh kayu putih dengan skor minimum disebut kriteria $\operatorname{Rmin}^{(12,13)}$.

\begin{tabular}{|c|c|c|c|}
\hline Indeks Lahan & Kelas Kesesuaian & Simbol & Pengertian \\
\hline $75-100$ & Sangat Sesuai (Kelas 1) & $\mathrm{S}_{1}$ & $\begin{array}{l}\text { Tanpa atau sedikit pembatasan untuk } \\
\text { penggunaannya }\end{array}$ \\
\hline $50-75$ & Sesuai (Kelas 2) & $\mathrm{S}_{2}$ & $\begin{array}{l}\text { Tingkat pembatasan sedang untuk } \\
\text { penggunaanya }\end{array}$ \\
\hline $25-50$ & Sesuai marginal (Kelas 3) & $\mathrm{S}_{3}$ & Tingkat pembatas berat untuk penggunanya \\
\hline $12.5-25$ & Tidak sesuai saat ini (Kelas 4) & $\mathrm{N}_{1}$ & $\begin{array}{l}\text { Penggunaanya tidak memungkinkan untuk saat } \\
\text { ini }\end{array}$ \\
\hline $0-12.5$ & Tidak sesuai permanen (Kelas 5) & $\mathrm{N}_{2}$ & $\begin{array}{l}\text { Penggunaannya tidak memungkinkan scara } \\
\text { permanen }\end{array}$ \\
\hline
\end{tabular}

Tabel 1. Klasifikasi kelas kesesuaian lahan berdasarkan nilai indeks lahan

Sumber : Sadono et., al. 2019(3) 
Selanjutnya sesuai dalam penilaian kesesuaian lahan, ada tiga faktor utama yang harus diperhatikan. Faktor tersebut (a) kebutuhan atau persyaratan tumbuh tanaman (crop requirements), (b) kebutuhan atau persyaratan pengelolaan (management requirements), dan (c) kebutuhan atau persyaratan konservasi (conservation requirements). Orientasi lahan untuk peningkatan pertumbuhan dan produksi tanaman, serta ramah lingkungan (mampu menahan erosi). Sehingga pengumpulan dan analisis berbagai data akan menghasilkan data primer analisa lahan, lingkungan, serta tanaman kayu putih. Pengumpulan data berasal dari penelitian terdahulu, publikasi ilmiah yang sudah dipublikasikan ditambahkan hasil penelitian terbaru melalui analisa laboratorium dan studio.

\section{HASIL DAN PEMBAHASAN}

Lahan kritis (critical land) di sub DAS Citarum Hulu di Desa Cikembang yang terbentuk berupa hamparan lahan mengalami penurunan daya dukung sehingga tidak mampu kembali menopang pertumbuhan tanaman serta rawan akan bahaya banjir dan erosi(14). Lahan kritis diakibatkan adanya kegiatan yang melebihi kemampuan lahan seperti kegiatan penggunaan lahan yang tidak sesuai peruntukannya. Selain itu terdapatnya kegiatan konversi kawasan menjadi areal pertanian, perkebunan pemukiman serta kegiatan yang kurang terencana dengan baik juga mempercepat terbentuknya lahan kritis ${ }^{(14)}$. Kondisi tersebut menjadi penyebab lahan sub DAS Citarum Hulu di Desa Cikembang mengalami lahan kritis. Kebiasaan masyarakat Desa Cikembang, masih melakukan pola pertanian untuk tanaman semusim seperti wortel, kubis, kacang panjang, ubi, dan kentang yang bisa langsung dipanen dalam waktu 3 hingga 6 bulan yang dapat bermanfaat jangka pendek. Sehingga konservasi menjadi penting dalam upaya mempertahankan atau memperbaiki daya guna lahan termasuk kesuburan tanah dengan teknik pola tanam (vegetatif) maupun silvikultur untuk memberikan perlindungan, perbaikan, dan pemakaian sumber daya alam yang berprinsip menjamin keuntungan ekonomi atau sosial scara alami. Dalam penelitian ini diperoleh hasil analisis kesesuaianlahan, tanaman kayu putih, modifikasi konservasi, serta efektifitas pengelolaan yang berdaya guna selain konservasi juga dapat menjadi nilai tambah, sebagai berikut:

\subsection{Analisis Kesuburan Tanah}

Analisa tanah dengan sampel lapisan tanah yang mewakili peta tanah yaitu lapisan atas 0-
$20 \mathrm{~cm}$ serta lapisan bawah $20-50 \mathrm{~cm}$ mewakili tingkat kesuburan tanah dengan unsur dan sifat kimia tanah kadar $\mathrm{pH}$, Fosfat, dan Kalium ${ }^{(13)}$ sesuai kriteria nilai analisa di Laboratorium Tanah Universitas Padjadjajaran (UNPAD). Pengamatan karakter fisik, kimia, dan lingkungan(12), diperoleh sampel dari ketiga lokasi lahan yaitu:

(a) Media perakaran (tekstur tanah, drainase serta kedalaman efekftif)

Karakter faktor pembatas syarat tumbuh tanaman kayu putih, tekstur tanah di lokasi penelitian tidak menjadi faktor pembatas pengembangannya. Tekstur tanah di lokasi penelitian tergolong lempung berpasir untuk lahan Tb/basah sedang), lempung berpasir di lahan Tk/lahan kemiringan dan lahan Tm/deket mata air. Keadaan lahan tersebut tergolong sangat sesuai untuk pengembangan kayu putih, dengan tidak dicirikan oleh adanya motling/karatan serta ciri glei pada lahan penelitian. Hasil pengamatan di tiga lokasi pengamatan lapangan dengan penggalian lahan terpilih dengan kedalaman sangat dangkal $(15 \mathrm{~cm}-$ $60 \mathrm{~cm}$ ). Secara efektif sesuai syarat lahan pengembangan kayu putih berkisar dari $\mathrm{S} 2$ (cukup sesuai) yaitu lempung berpasir, tidak ada genangan air $>60 \mathrm{~cm}$.

(b) Kapasitas tukar kation, kejenuhan basa, pH tanah, dan C-organik (kualitas Iahan retensi hara)

Kapasitas Tukar Kation (KTK) cukup sesuai dengan kebutuhan pengembangan tanaman kayu putih yaitu rata-rata 33,06\% (kategori tinggi). Untuk tingkat kejenuhan basa relatif rendah, dan sangat rendah di lokasi lahan Tk/lahan kemiringan, hal ini disebabkan karena curah hujan yang cukup tinggi, sebagai pencuci intensif terhadap basa-basa lahan di lokasi penelitian. Selanjutnya $\mathrm{pH}$ tanah untuk tanaman kayu putih lebih disukai jenis $\mathrm{pH}$ tanah yang cenderung masam, jika $\mathrm{pH}$ tinggi (netral) untuk pertumbuhan menghambat. Kondisi $\mathrm{pH}$ tersebut sesuai dengan lahan ketiga lokasi dengan nilai $\mathrm{pH}$ relatif masam $(5,84-6,35)$. Kandungan C-organik dalam ketiga lokasi lahan yaitu rata-rata sedang. Kondisi ini karena lahan relatif sering digunakan untuk aktifitas tanaman musiman (tanaman sayuran, tumpangsari cabai, dan kentang) dengan penambahan kandungan organik yang kurang. Karakter ini membuat tanah peka terhadap erosi, akibat menurunnya agregasi tanah tersebut. 
(c) Tingkat kualitas lahan akan ketersediaan $\mathrm{N}$-total, $\mathrm{P}_{2} \mathrm{O}_{5}$ tersedia, dan $\mathrm{K}_{2} \mathrm{O}$

Lahan penelitian untuk $\mathrm{N}$-total tanah ketiga lokasi lahan menunjukkan nilai sedang $(0,37-0,39)$, kondisi ini cukup dapat menjadi penguat pertumbuhan tanaman kayu putih, akan tetapi kandungan bahan organik tanah dan aktifitas penghambat penguapan unsur $\mathrm{N}$ dari tanah perlu dilakukan. Selanjutnya untuk ketersediaan lahan akan ketersediaan fosfat termasuk sangat tingi untuk ketiga lahan $(13,41-54,33 \mathrm{ppm})$, sehingga dapat mendukung pengembangan tanaman kayu putih. Kalium yang terkandung dalam ketiga lahan memiliki kandungan yang sangat tinggi, dan tinggi $(42,25-62,25 \mathrm{mg} / 100 \mathrm{~g})$, kondisi tersebut bersifat dapat mendukung pertumbuhan tanaman kayu putih, akan tetapi keseimbangan pemupukan, baik pemupukan organik dan anorganik dengan kandungan unsur $\mathrm{K}$ tetap diperhatikan untuk hasil pertumbuhan yang diharapkan.

(d) Potensi mekanisasi/lahan terrain (lereng, batuan, permukaan, dan singkapan lahan)

Kondisi lereng, batuan permukaan, dan singkapan lahan untuk ketiga lokasi menunjukkan berpotensi diolah dengan mekanisasi yang cukup mudah. Sehingga kondisi lahan tersebut memungkinkan dapat menjadi faktor pertumbuhan akar tanaman kayu putih, yaitu: lempung serta lempung berpasir.

\section{(e) Kualitas lahan terhadap tingkat erosi}

Faktor kualitas lahan terhadap tingkat erosi ketiga lokasi menunjukkan kisaran sangat tinggi. Kondisi tersebut dengan ditandainya fisik lahan tingkat kemiringan lereng yang cukup miring dan kondisi tingkat tanah yang peka terhadap erosi.

\subsection{Analisis Prasyarat Tumbuh Kayu Putih dengan Lahan Konservasi}

Pertumbuhan yaitu suatu proses kemajuan perkembangan dengan faktor lingkungan yang dialami oleh tanaman yang dapat hidup di lingkungan serta dukungan sifat-sifat tertentu sebagai prasyarat. Hasil pengamatan lapangan dan analisis laboratorium dilakukan interprestasi berdasarkan kondisi tanah di lapangan, yaitu dengan evaluasi kesesuaian lahan dilakukan dengan pola matching systems yaitu membandingkan hasil analisa kimia tanah dengan prasyarat tumbuh tanaman kayu putih ${ }^{(3)}$.

Keadaan fisik tanah dan lingkungan dilakukan pendataan untuk keperluan evaluasi, interprestasi lahan untuk komoditas tertentu ${ }^{(15)}$. Sesuai dengan klasifikasi geomorfologi yang dibakukan ${ }^{(16)}$, diperoleh hasil perbandingan pada lahan konservasi di Desa Cikembang, yaitu untuk tingkat elevasi ketiga sampel berlokasi di terletak pada kategori pegunungan atau ketinggian relatif $>1.000 \mathrm{mdpl}$. Kelerengan lahan pada ketiga lokasi sampel memiliki tingkat kelerengan $15-20 \%$ : lereng agak curam, serta lereng landai $(10-15 \%)$, sebagaimana dalam ditunjukan dalam Tabel 2. Variasi suhu dari setiap lokasi sampel lahan memiliki rentang 18 $25{ }^{\circ} \mathrm{C}$ hampir memiliki kesamaan rentang. Demikian juga untuk dengan curah hujan juga terdapat rentang yaitu $1.000-3.000 \mathrm{~mm} / \mathrm{tahun}$, yaitu tergolong intensitas rendah. Tingkat kemasaman tanah pada ketiga lokasi sampel tergolong agak masam yaitu (a) tanah basah/Tb: 6,35 , (b) tanah kemiringan/Tk: 5,84, (c) tanah dekat mata air/Tm: 5,94. Tingkat kemasaman dan kandungan organik di ketiga lokasi sampel yaitu kisaran $7-8 \%$ dengan kategori agak masam, kondisi tersebut untuk ketiga lokasi memliki lahan dengan kandungan organik yang termasuk sangat tinggi dan sangat peka terhadap tingkat erosi.

Tabel 2. Karakteristik lahan untuk tanaman kayu putih di Desa Cikembang

\begin{tabular}{llcc}
\hline \multicolumn{1}{c}{ Parameter lahan } & \multicolumn{1}{c}{ Tanah basah/Tb } & Tanah kemiringan (Tk) & Tanah dekat mata air/Tm \\
\hline Elevasi $(\mathrm{m} \mathrm{dpl)}$ & 1.600 & 1.700 & 1.700 \\
Kelerengan $(\%)$ & $10-15$ & $15-20$ & $15-20$ \\
Suhu $\left({ }^{\circ} \mathrm{C}\right)$ & $20-25$ & $18-24$ & $18-23$ \\
Curah hujan (mm/tahun) & $1.000-2.000$ & $1.000-2.000$ & $1.000-3.000$ \\
Kemasaman tanah $\left(\mathrm{pH} \mathrm{H} \mathrm{H}_{2} \mathrm{O}\right)$ & $6,10-6,35$ & $4,42-5,84$ & $4,01-5,94$ \\
C organik $(\%)$ & 3,12 & 2,64 & 2,91 \\
\hline
\end{tabular}

Sumber: Data primer diolah (2020)

Penggunaan lahan dapat mempengaruhi intensitas erosi. Hal tersebut dipengaruhi oleh vegetasi yang terdapat di suatu kawasan lahan, seperti hutan misalnya yang pada umumnya memiliki vegetasi dengan akar yang kuat serta mampu menahan laju erosi permukaan. Tutupan lahan berupa hutan memiliki daun yang rimbun termasuk seresah yang mampu 
memperlambat jatuhya laju air hujan ke permukaan tanah(17). Penggunaan lahan di Desa Cikembang yang belum sesuai yaitu antara kawasan budi daya dan kawasan lindung. Kondisi tersebut seiring dengan peningkatan populasi penduduk, meningkat pula kebutuhan lahan budi daya. Guna pemantauan dan menjaga keseimbangan kawasan lahan dipilih tanaman kayu putih yang sesuai/cocok untuk konservasi vegetatif di lahan konservasi(14). Konservasi tanah dengan vegetasi tanaman kayu putih mempunyai prospek untuk dapat diterima oleh masyarakat petani di Indonesia(18), di Desa Cikembang pada khususnya. Dengan pemilihan vegetasi tanaman kayu putih serta kecocokannya dengan lahan konservasi, selanjutnya digunakan untuk upaya mendukung pengembangan kayu putih di Desa Cikembang dengan strategi pengelolaan dengan teknik silvikultur.

\subsection{Analisis Lingkungan Pembatas dengan Prasyarat Tumbuh Tanaman Kayu Putih}

Curah hujan harian di sub DAS Citarum Hulu di Desa Cikembang yaitu hujan maksimum mencapai $36,0 \mathrm{~mm}$, jumlah curah hujan 1.093,2 $\mathrm{mm}$, dengan jumlah hari hujan 73 hari, kemudian hujan ekstrim 360 hari. Dengan kondisi klimatologi sub DAS Citarum Hulu di Desa Cikembang untuk temperature udara ratarata: $25,3{ }^{\circ} \mathrm{C}$, temperatur air rata-rata: $27,9{ }^{\circ} \mathrm{C}$, rata-rata penguapan $5,0 \mathrm{~mm}$, kecepatan angin rata-rata:53,7 $\mathrm{km} /$ hari serta lama penyinaran matahari rata-rata $52 \%$. Kondisi lingkungan pembatas berdasarkan klasifikasi iklim menuruttipe hujan di daerah ini termasuk tipe iklim A (amat basah) ${ }^{(9,15)}$. Suhu udara normal bulan terdingin lebih dari $18{ }^{\circ} \mathrm{C}$, suhu bulan terpanas $25,3{ }^{\circ} \mathrm{C}$. kondisi iklim tersebut dapat menjadi faktor penunjang keberhasilan budidaya tanaman kayu putih. Lama waktu penyinaran matahari daerah juga cukup lama yaitu 52\%, dengan curah hujan 1.093,2 mm, dan temperatur air sesuai dengan prasyarat tumbuh tanaman kayu putih di iklim tropis. Akan tetapi hujan yang cukup ekstrim dengan tanaman kayu putih dapat menjadi tanaman konservasi penahan erosi dan atau run off dengan teknik pola tanam.

\subsection{Analisis Tanaman Kayu Putih sebagai Tanaman Konservasi}

Identifikasi lapangan menunjukkan bahwa tanaman kayu putih (Melaleuca cajuputi sub sp. cajuputi) yang ditanam di Desa Cikembang. Jenis tanaman ini mempunyai daur biologis yang Panjang, cepat tumbuh, dapat tumbuh baik pada lahan-lahan marginal, mampu beradaptasi pada tanah berdrainase baik maupun jelek dengan kadar garam tinggi maupun asam dan toleran ditempat terbuka serta tahan terhadap kebakaran(19). Kayu putih mampu hidup dan tumbuh dalam 1 tahun dengan kondisi daundaun yang sudah dapat dipetik. Akan tetapi, tanaman kayu putih kurang tahan terhadap tanah dengan kadar keasaman 3 yang tinggi. Akar kayu terdiri dari akar tunggang, akar lateral, serta akar sekunder. Akar tunggang lurus dan tumbuh ke bawah, akar lateral tumbuh pada leher akar, dan akar sekunder menyebar pada kedalaman sekitar $20 \mathrm{~cm}$ di bawah permukaan tanah. Kayu putih dapat tumbuh menjadi pohon tinggi mencapai $35 \mathrm{~m}$ dengan diameter mencapai $100 \mathrm{~cm}^{(19)}$. Akan tetapi kayu putih dapat dimanipulasi untuk dapat menjadi perdu dengan cara memetik daunnya sejak tanaman berumur masih muda. Kayu putih selain dapat menahan laju air dengan curah hujan yang cukup tinggi, tanaman kayu putih dapat dimanfaatkan sebagai tanaman bahan baku industri. Bahan baku tersebut yaitu daun dari tanaman kayu putih dapat dimanfaatkan untuk disuling menjadi minyak atsiri yang bernilai ekonomi tinggi.

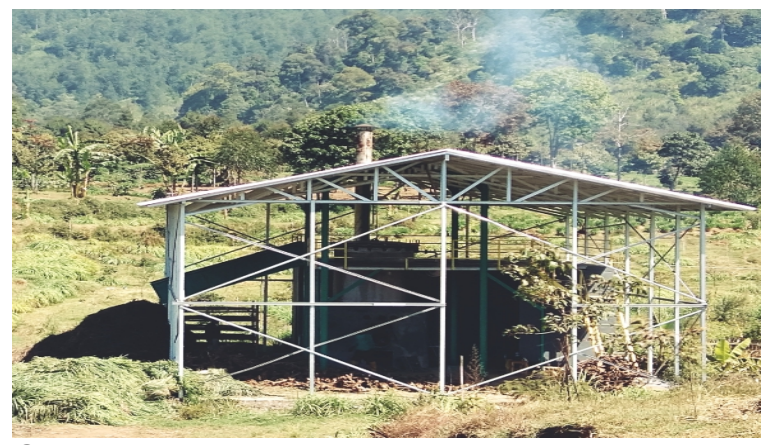

Gambar 1. Mesin penyulingan minyak atsiri di Kecamatan Kertasari, Kabupaten Bandung, Sumber: Dokumentasi Penelitian

Kegiatan konservasi dengan penanaman tanaman kayu putih dengan system MPTS (Multi Purpose Tree Spesies) yaitu menanam kayu putih sebagai tanaman konservasi selain tanaman pertanian yang dilakukan oleh Sektor 23 Citarum Harum sudah berjalan, akan tetapi respon masyarakat/petani belum semuanya dapat menerima sistem tersebut, dari 60 petani pemilik/penggarap, hanya sekitar 10 petani pemilik/penggarap yang menanam kayu putih. Hal tersebut perlu strategi, di mana konservasi dengan tetap memperhatikan keseimbangan penggunaan lahan dengan tanaman kayu putih, perlunya menguatkan sektor ekonomi kreatif dengan mengembangkan produk-produk inovatif $^{(20)}$ dari tanaman kayu putih, serta produksi tanaman kayu putih di lahan kritis yang dikembangkan di desa tersebut. Seperti halnya potensi penyulingan minyak sereh di Kecamatan 
Kertasasi dapat menjadi alternatif untuk proses penyulingan menjadi produk inovatif, sebagaimana dalam Gambar 1.

\subsection{Strategi Pengelolaan untuk Kebutuhan Modifikasi Konservasi dengan Tanaman Kayu Putih}

Pendekatan tata cara evaluasi kesesuaian lahan dengan metode root square dengan hasil luaran yang realistis untuk suatu budidaya sektor kehutanan, pertanian serta perkebunan sesuai dengan strategi modifikasi konservasi(3). Metode root square tersebut untuk sebuah hasil informasi lebih relevan/akurat guna keperluan pengembangan tanaman secara komersial, jika dibandingkan dengan metode storie. Hasil penilaian (Tabel 3) dengan metode storie ditunjukkan bahwa kelas kesesuaian lahan untuk ketiga lahan penelitian tergolong kategori $\mathrm{N}_{1} \quad$ (tidak sesuai untuk saat ini atau penggunaanya tidak memungkinkan untuk saat ini). Nilai tersebut berbeda dengan hasil metode root square dengan hasil yang cukup memperlihatkan kesesuaian lahan penelitian dengan sesuai marginal (S3) atau dengan tingkat pembatas berat untuk penggunaanya.

Tabel 3. Kelas kesesuaian lahan untuk tanaman kayu putih di Desa Cikembang

\begin{tabular}{lccccc}
\hline \multirow{2}{*}{ Lokasi Sampel Tanah } & \multicolumn{5}{c}{ Indeks Kesesuaian Lahan } \\
\cline { 2 - 6 } & Storie & Kelas Kesesuaian & Root Square & Kelas Kesesuaian & Faktor Pembatas \\
\hline Tanah basah/Tb & 25,08 & $\mathrm{~N}_{1}$ & 39.05 & $\mathrm{~S}_{3}$ & $\mathrm{~S} \mathrm{R}$ \\
Tanah kemiringan/Tk & 24.05 & $\mathrm{~N}_{1}$ & 38.41 & $\mathrm{~S}_{3}$ & $\mathrm{~A} \mathrm{R}$ \\
Tanah deket mata air /Tm & 24.68 & $\mathrm{~N}_{1}$ & 38.67 & $\mathrm{~S}_{3}$ & $\mathrm{~A} \mathrm{SOC}$ \\
\hline
\end{tabular}

Sumber: Data primer diolah (2020)

Beberapa atribut lahan yang menjadi faktor pembatas lahan untuk keseuaian di lokasi penelitian: (a) tanah basah/Tb yaitu tingkat kelerengan (simbul "S") serta tingkat curah hujan (simbul "R"); (b) tanah kemiringan/Tk yaitu tingkat elevasi (simbul "A") dan curah hujan (simbul "R"); (c) tanah deket mata air/Tm yaitu tingkat C-organik (simbul "SOC").

Hasil penelitian sifat lahan digunakan sebagai strategi pengelolaan untuk kebutuhan modifikasi konservasi dengan tanaman kayu putih, Gambar 2 menguraikan strategi pengelolaan untuk kebutuhan modifikasi konservasi dengan tanaman kayu putih dengan acuan hasil kesesuaian lahan yaitu: (a) elevasi; (b) kelerengan suatu lahan; (c) curah hujan, serta (d) kadar bahan organik. Yaitu variasi suhu dalam lahan lokasi penelitian tidak terdapat rentang perbedaan, meskipun terdapat perbedaan tingkat elevasi. Kondisi ini tidak dapat di modifikasi konservasi dengan tanaman kayu putih dengan aplikasi teknik silvikultur. Demikian juga variabel topografi tidak dapat dimodifikasi dengan menggunakan teknik silvikultur ${ }^{(3)}$. Namun, studi ini menemukan adanya perbedaan variasi suhu yang disebabkan oleh atribut yang dinamakan elevasi.

Potensi erosi disebabkan oleh tingkat kelerengan serta curah hujan, semakin kelerengan tinggi serta curah hujan dengan intensitas tinggi, maka tingkat erosi semakin besar. Untuk mengurangi tingkat erosi dengan curah hujan di lokasi penelitian yang cukup tinggi dilakukan strategi modifikasi konservasi dengan pola tanam seperti pada Gambar 3 pola tanam dengan pengaturan mengarah ke lereng dengan tingkat kerapatan $3 \times 1$ meter, sehingga dapat menghambat laju aliran permukaan penyebab erosi. Implementasi pola tanam di Desa Cikembang yaitu $3 \times 1 \mathrm{~m}$, dalam satu hektar dapat memuat tanaman kayu putih sebanyak 3.333 pohon, dengan asumsi produksi pangkasan bahan baku minyak kayu putih sebanyak $6 \mathrm{~kg} /$ pohon, sehingga dalam satu kali panen akan menghasilkan $19.998 \mathrm{~kg}$ daun/ha(6). Untuk rata-rata rendemen $2 \%$, dapat menghasilkan minyak kayu putih $399,96 \mathrm{~kg}$ minyak/ha(6).

Selanjutnya untuk konservasi lingkungan, modifikasi konservasi dapat sejalan dengan motivasi peningkatan ekonomi petani dengan pemanfaatan tanaman kayu putih, terutama untuk bahan baku industri minyak kayu putih dengan proses penyulingan ${ }^{(21)}$. Kegiatan penanaman, pemeliharaan seperti pemupukan, penghijauan kembali lahan baik pada tegakan monokultur maupun campuran meningkatkan unsur hara, kadar $\mathrm{C}$ dan total aktivitas mikroba dalam tanah(22). Hal tersebut dilakukan untuk menjaga ketersediaan nutrisi tanaman kayu putih sesuai dengan kondisi konsentrasi bahan organik atas tanah. Proses pemupukan perlu dilakukan secara terkontrol untuk peningkatan kemasaman tanah. Hal ini untuk modifikasi tanah dan upaya-upaya untuk mempertahankan serta meningkatkan kondisi lahan yang masih 
baik produktivitasnya agar dapat berfungsi secara optimal, baik sebagai unsur produksi, media pengatur tata air, maupun sebagai unsur perlindungan alam lingkungan ${ }^{(23)}$. Unsur produksi pada lahan yang berfungsi optimal tersebut dapat meningkatkan tingkat produksi bahan baku minyak kayu putih.

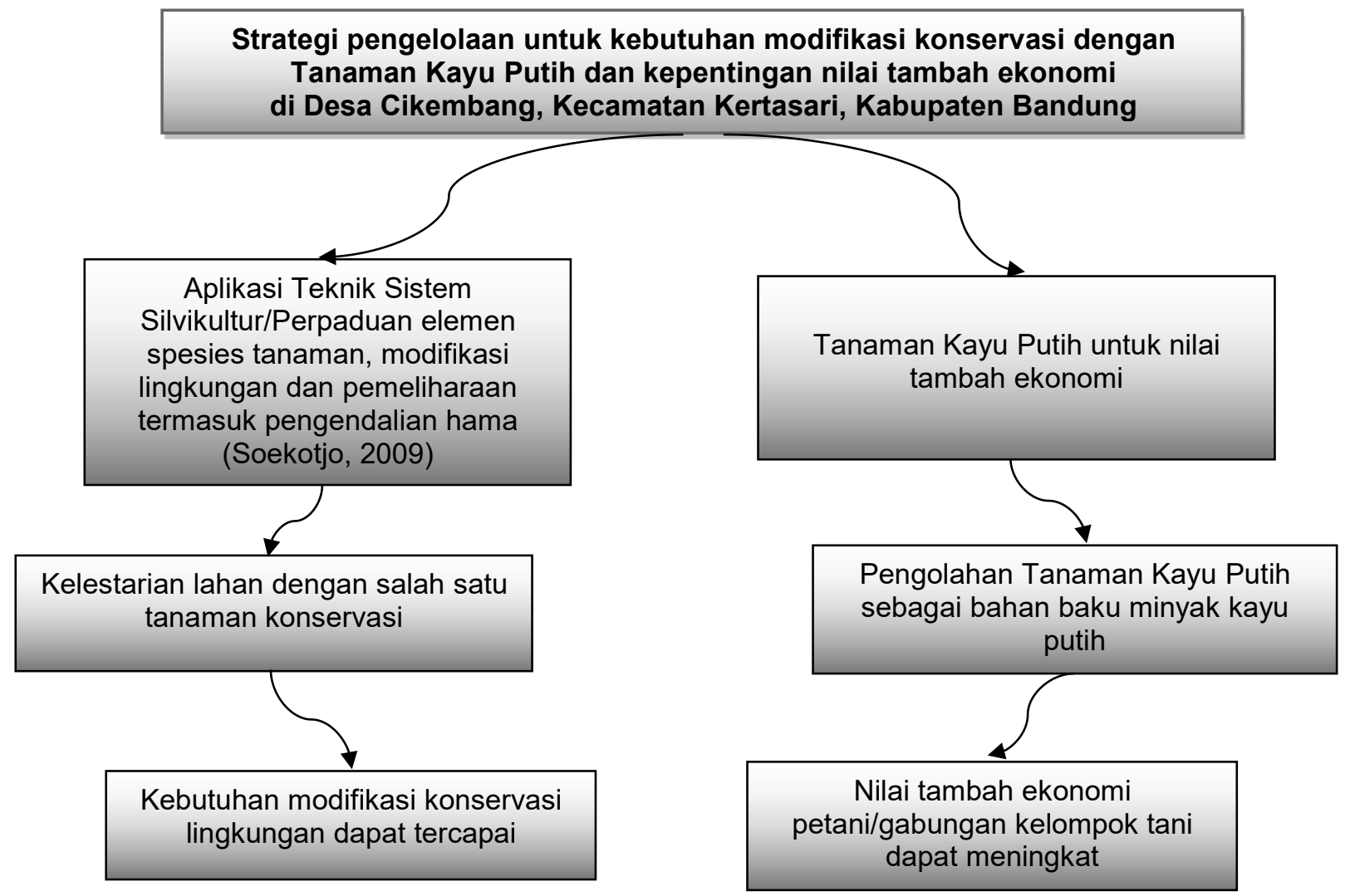

Gambar 2. Bagan alir strategi pengelolaan untuk kebutuhan modifikasi konservasi dengan tanaman kayu puith dan kepentingan nilai tambah ekonomi, di Desa Kertasari, Kecamatan Kertasari, Kabupaten Bandung, Sumber: Hasil Penelitian

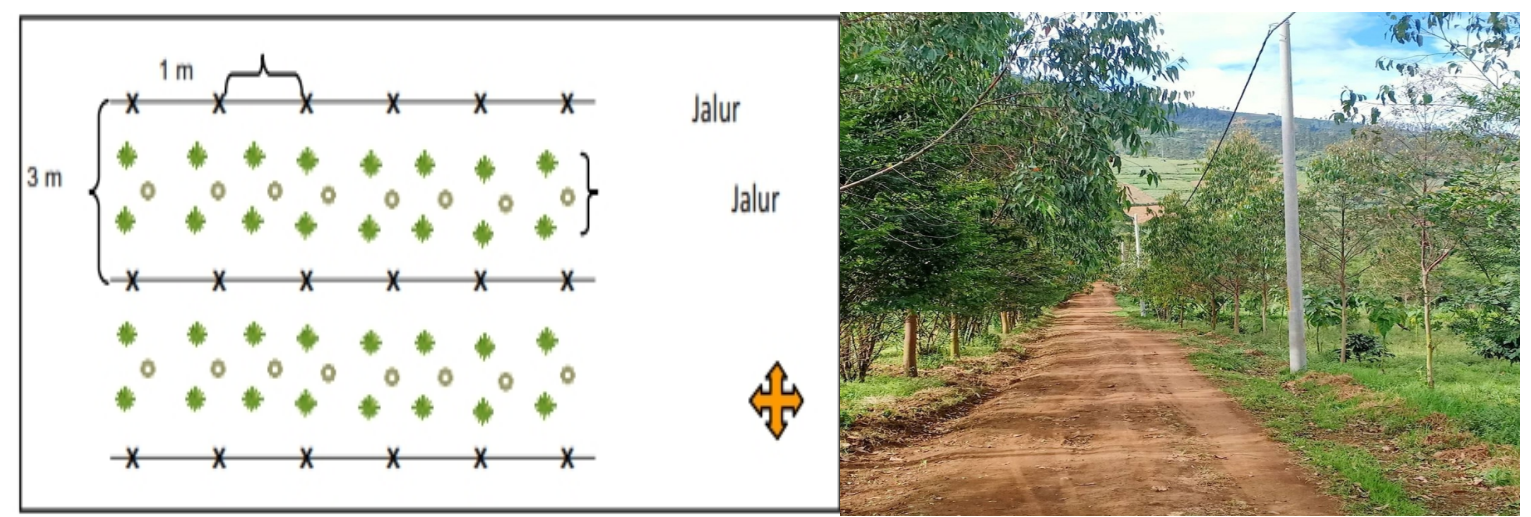

Gambar 3. Tanaman kayu putih dengan pola tanam serta pengaturan jarak. Keterangan : $\mathrm{x}=$ titik jarak tanam kayu putih. Sumber: Dokumentasi Penelitian

\section{KESIMPULAN}

Indeks kesesuaian lahan di sub DAS Citarum Hulu Desa Cikembang dengan metode Root Square untuk ketiga lokasi tergolong S3 (sesuai marginal), RS (Root Square) lokasi lahan basah/Tb: 39.05, faktor pembatasnya: $\mathrm{S}$ (kelerengan), dan R (curah hujan); RS (Root Square) lokasi lahan kemiringan/Tk: 34.41, faktor pembatas A (elevasi) dan R (curah hujan); RS (root square) lokasi lahan dekat mata air/Tm :38.67, faktor pembatas A (elevasi) dan SOC (kandungan C-organik). Analisis kesesuaian lahan untuk kayu putih menunjukkan tanaman kayu putih (Melaleuca cajuputi sub sp. cajuputi) yang ditanam di Desa Cikembang cepat tumbuh, dapat tumbuh baik 
pada lahan-lahan marginal. Berdasarkan hasil analisis kesesuaian lahan tersebut, analisis atribut pembatas lingkungan, penggunaan lahan untuk tanaman kayu putih tergolong baik dan perlu dipertahankan penyebarannya terutama pada lahan yang mempunyai kemiringan lereng curam. Selain itu, tata guna lahan dengan mengakomodasi pola tanam untuk kepentingan konservasi dan kepentingan pertanian dapat berpotensi mengurangi intensitas erosi yang akan terjadi di Desa Cikembang.

Desa Cikembang beberapa tahun ke depan berpotensi dikembangkan, baik dalam hal perubahan fungsi tata guna lahan maupun sarana dan prasarana. Kondisi tersebut akan berimplikasi terhadap peningkatan pemanfaatan lahan untuk tanaman kayu putih. Hal ini bertujuan agar keseimbangan antara fungsi konservasi dan kepentingan nilai tambah tanaman kayu putih itu sendiri. Oleh karena itu, strategi modifikasi konservasi dengan tanaman kayu putih perlu dilakukan dengan (a) pendekatan aplikasi teknik sistem silvikultur (pemaduan elemen spesies tanaman, modifikasi lingkungan, pembuatan teras, pengaturan jarak tanam, pengaturan pemupukan, pemeliharaan, termasuk pengendalian hama), serta (b) pendekatan tanaman kayu putih sebagai penghasil bahan baku penyulingan minyak kayu putih untuk nilai tambah ekonomi.

\section{PERSANTUNAN}

Penulis ucapkan terima kasih banyak Kepada Bapak Prakoso Bhairawa Putera, S.IP., M.A., (Kepala Biro Perencanaan dan Keuangan LIPI), Bapak Danang Heru Prasetyo, M.Sc., Ibu Rr. Widhya Yusi Samirahayu, SE, MT., Bapak Poerwanto Soeseno, SE. MM., dan tim di Fungsi Monitoring Evaluasi BPK LIPI Kawasan Bandung, pengelola program By-Research LIPI, Komandan Sektor Satgas Citarum Harum/Bapak Kolonel Arh. Wahyu J, beserta jajarannya, dan Reza Nugraha (pendamping Gapoktan Desa Cikembang) atas dukungan yang diberikan selama ini.

\section{DAFTAR PUSTAKA}

1. Aditya Al-Fikri Amanullah, A. A., Putra, A., Aprillian, A., Cahyani, A.T., Pangestu, C., Effendi, E., Alyandri, F. H., Putra, G.H., Syafrina, Khamsya, V.J., Risky Ramadhan, R.R. (2020). Morfologi Alluvial Plain Desa Bumiwangi Kecamatan Ciparay. Jurnal Buana. 4 (5):451-465.

2. Satuan Tugas Pengendalian Pencemaran dan Kerusakan DAS Citarum Provinsi Jawa Barat. (2019). Rencana Aksi Pengencalian dan Pencemaran Kerusakan DAS Citarum 20192025.
3. Sadono, R., Soeprijadi, D., Wirabuana, P. Y. A. P., (2020). Kesesuaian lahan untuk pengembangan tanaman kayu putih dan implikasinya terhadap teknik silvikultur. Journal of Natural Resources and Environmental Managemen. JPSL. 10 (1):4351. doi:10.29244/jpsl.10.1.43-51.

4. Dan, Y.A., Amayanti, E. L. K. D., (2012). Pemanfaatan dan Uapaya Konservasi Kayu Putih di Taman Nasional Wasur. Media Konservasi. 17(2):85-93. doi:10.29244/medkon.17.2.\%p.

5. Wedhana, I. B., Idris, M. H., Silamon, R. F., (2018). Analisis Pertumbuhan Tanaman Kayu Putih (Melaleuca cajuputi sub sp. cajuputi) Pada Kawasan Hutan Lindung Dusun Malimbu Dan Dusun Badung Resort Malimbu KPHL Rinjani Barat. Jurnal Belantara[JBL]. 1 (1):35-44. doi:10.29303/jbl.v1i1.13.

6. Badan Penelitian dan Pengembangan Kehutanan. (2014). Budidaya Dan Prospek Pengembangan Kayu Putih (Melaleuca Cajuputi). Jakarta. IPB Pess.

7. Febry R.Torry, F. R., \& Idrus, S. (2016). Pemetaan Kualitas Minyak Kayu Putih (Melaleuca leucadendra) di Maluku. Majalah BIAM. 12(01):14-19.

8. Lestari, J. D., Simatupang, D. O. (2018) Analysis of Development Strategy Eucalyptus Oil Refinery Business. Agricola. 8 (1):42-50.

9. Juniarti, Yulnafatmawiyata, Isminingsih, $\mathrm{S}$. (2007). Evaluasi Kesesuaian Lahan dan Potensi Produksi Tanaman Manggris (Garciana mangostana L.) Di Kab.50Kota. Jurnal Tanah. 14-22 ISSN: 1829-7994. Published online 1976:14-22.

10. Lahan., A., K., Teknik,. J., Teknik., F. (2017). Metode Teknik Perencanaan (Analisis Kesesuaian Lahan). Yogyakarta. Magister Perencanaan Kota dan Daerah, Jurusan Teknik Arsitektur dan Perencanaan, Fakultas Teknik, UGM.

11.Mulyani, A., \& Besar, B., (2018). Modifikasi Metode Evaluasi Kesesuaian Lahan Berorientasi Perubahan Iklim. Jurnal Sumberdaya Lahan. 12(1):1-11. doi:10.2018/jsdl.v12i1.8228.

12. Dibia, I., (2015). Evaluasi Kesesuaian Lahan Untuk Pengembangan Tanaman Kayu Putih (Malaleuca Leucadendra) Pada Kawasan Hutan Produksi Bali Barat (Kecamatan Grokgak) Kabupaten Buleleng Bali. Agrotrop Journal on Agriculture Science. 5(2):196-207.

13. Sudaryono. (2010). Evaluasi Kesesuaian Lahan Tanaman Kayu Putih Kabupaten Buru, 
Provinsi Maluku. Jurnal Teknololgi Lingkungan. $\quad$ 11(1):105. doi:10.29122/jtl.v11i1.1228.

14. Wahyudi. (2014). Teknik Konservasi Tanah serta Implementasinya pada Lahan Terdegradasi Dalam Kawasan Hutan (Soil Conservation Technique and Its Implementation in the Degraded Land of Forest Regions). Jurnal Sains dan Teknol Lingkungan. 6(2):71-85.

15. Setiawan, B., Yudono, P., Waluyo, S. (2018). Evaluasi Tipe Pemanfaatan Lahan Pertanian dalam Upaya Mitigasi Kerusakan Lahan Di Desa Giritirta, Kecamatan Pejawaran, Kabupaten Banjarnegara. Vegetalika. 7(2):1. doi:10.22146/veg.35769.

16.Bermana, I. (2006). Klasifikasi geomorfologi untuk pemetaan geologi yang telah dibakukan. Bulletin of Scientific Contribution. Volume 4(2):161-173.

17. Sulaksana, N., Sjafrudin, A., Sukiyah, E., Raditya, P., P., Abdulah, F., Setiyanto, P. (2015). Peran Tata Guna Lahan Terhadap Distribusi Tingkat Kerawanan Erosi Di Kawasan Ciletuh Jawa Barat. Bulletin of Scientific Contribution. 13:160-167.

18. Subagyono, K., Marwanto, S., Kurnia, U. (2003). Seri Monograf 1: Teknik Konservasi Tanah Secara Vegetatif. Bogor. Balai Penelitian Tanah Pusat Penelitian dan Pengembangan Tanah dan Agroklimat, Badan Penelitian dan Pengembangan Pertanian, Departemen Pertanian.

19.B Triana, N. (2018, Selasa, 6 Maret 2018). https://nenytriana.wordpress.com/2018/03/06/ analisis-kesesuaian-lahan-untuk-tanamankayu-putih-melaleuca-leucadendron-di-kphprote-ndao-dengan-menggunakan-sisteminformasi-geografis/. pdf. 2014;7:219-232.

20. Endyana, C. (2019). Peningkatan Kualitas Lingkungan Hidup Dengan Pengembangan Ekonomi Kreatif Warga Desa Cileunyi Wetan Kabupaten Bandung. Kumawula: Jurnal Pengabdia Kepada Masyarakat. 2(3):201. doi:10.24198/kumawula.v2i3.24551.

21.Behuku, W., M., Kastanya, A., \& Pattimahu, D., V., (2016). Analisis Nilai Tambah Ekonomi ( Economy Value Added) Unutk Mengukur Kinerja Keuangan Petani Minyak Kayu Putih Desa Pela dan Batu Jungku di Wilayah Kerja Kesatuan Pengelolaan Hutan Produksi (KPHP) MODEL UNIT III WAE TINA. Jurnal Hutan Pulau-Pulau Kecil. 1(1):6671.doi:10.30598/jhppk.2016.1.1.66

22. De Oliveira Paulucio, V., da Silva, C., F., Martins, M., A., Pereira, M., G., Schiavo, J., A. \& Rodrigues, L., A. (2017). Reforestation of a degraded area with Eucalyptus and Sesbania: Microbial activity and chemical soil properties. Revista Brasileira de Ciencia do Solo. 41:1-14. doi:10.1590/18069657rbcs20160239.

23. Wahyuningrum, N., \& Basuki, T., M. (2019). Analisis kekritisan lahan untuk perencanaan rehabilitasi lahan DAS Solo bagian hulu. Jurnal Penelitian Pengelolaan Daerah Aliran Sungai. doi:10.20886/jppdas.2019.3.1.27-44. 